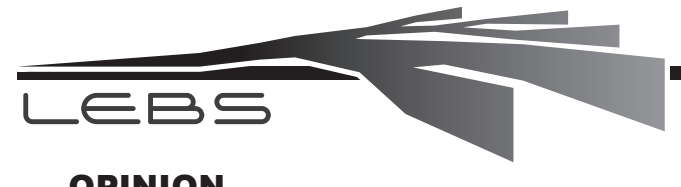

OPINION

\section{Education as Niche Construction: Toward an Evolutionary Science of Education}

\author{
Ryo Oda* \\ Nagoya Institute of Technology, Gokiso-cho, Showa-ku, Nagoya 466-8555, \\ Japan \\ *Author for correspondence (oda.ryo@nitech.ac.jp)
}

In humans, education is characterized by active teaching in a wide range of knowledge domains. The subjects taught include how to think and behave, norms and morals, and knowledge and skills, all of which directly increase the fitness of the pupils. Although many comparative and developmental studies have examined active teaching in humans, few have considered its ultimate factors, especially its adaptive significance. The evolution of education can be considered in the context of the evolution of altruistic behavior because tutors transmit adaptive information to pupils at a cost. The evolution of altruism can be explained by the positive assortment of genes related to altruism. However, a genetic basis for reciprocity is not a necessary condition for the evolution of reciprocal altruism. Reciprocal altruism is possible without positive assortment if mutually beneficial social relationships can be created culturally through education. Active teaching of reciprocal norms could be interpreted as niche construction for a social environment. The adaptive perspective presented here could lead to an evolutionary science of education in the future.

\section{Keywords}

education, active teaching, niche construction, reciprocity, norm, cultural transmission

\section{What is education?}

Education is one of the many unique human behaviors. Some dictionaries define education as something that takes place especially in a school or college. In this manuscript, I adopt a more general definition from Wikipedia: "Education is the process of facilitating learning or the acquisition of knowledge, skills, values, morals, beliefs, and habits." ("Education", 2021)1. At the behavioral level, education is implemented through active teaching. Caro and Hauser's widely adopted operational definition of active teaching is useful for scientific studies of education. This definition can be summarized as follows': (1) Individual actor A modifies their behavior only in the presence of naive observer B at some cost or at least without obtaining an immediate benefit; (2) A's behavior thereby encourages or punishes B's behavior, provides B with experience, or sets an example for B; (3) As a result, B acquires knowledge or learns a skill earlier in life or more rapidly or efficiently than they might otherwise do, or that they would not learn at all (Caro \& Hauser, 1992). Using this definition, teaching behavior has been observed in nonhuman species, such as meerkats (Suricata suricatta; Thornton \& McAuliffe, 2006), ants (Temnothorax albipennis; Franks \& Richardson, 2006), and birds (Turdoides bicolor; Raihani \& Ridley, 2008). Active teaching is not widespread or frequent among nonhuman species. By contrast, humans exhibit active teaching in a wide range of knowledge domains, and even infants show behaviors that involve trying to teach something to others (e.g., Liszkowski et al., 2006; Meng \& Hashiya, 2014), which suggests that active teaching is an adaptive human biological trait.

Few studies of active teaching in humans have considered its ultimate factors, especially its adaptive significance (i.e., the survival value of Tinbergen's four questions; Tinbergen, 1963). This manuscript focuses on the fitness of active teaching, especially toward non-kin. Characteristically, human education is large-scale and systematic, at least in the modern age, and what is taught is not limited to knowledge or skills that increase the pupils' fitness directly. In education, we are also taught how we should think and behave (e.g., customs, values, norms, morals, and ideology). For example, Article 1 of the Basic Act on Education in Japan states: "Education must be provided with the aim of fully developing the individual character, as we endeavor to cultivate a people that is sound in mind and body and imbued with the qualities that are necessary in the people who make up a peaceful, democratic nation and society" (Kyōiku kihonhō [Basic Act on Education], 2006). That is, the national aim of education is to complete the formation of each individual's character and to cultivate national and societal leaders. Interestingly, such education does not increase the pupils' fitness directly. If education does increase fitness, it does so by helping pupils adapt to their social environment.

\footnotetext{
In this manuscript, concrete actions for education are defined as active teaching and education is defined as including larger systems and processes of the active teaching. There are several other words that refer to teaching, such as instruction, coaching, and counseling. Although each dictionary has a different detailed definition, the Cambridge Dictionary, for example, refers to instruction as "the teaching of a particular skill or subject" coaching as "the act of giving special classes in sports, a school subject, or a work-related activity, especially to one person or a small group," and counseling as "the job or process of listening to someone and giving that person advice about his or her problems" (Cambridge University Press, n.d.) These are the more detailed and specific aspects of 'active teaching.' That is, active teaching in this manuscript includes these behaviors. ation. In this manuscript, I consider active teaching as what constitutes education when it is customary to some extent to teach several individuals other than kin members, even if not on a large scale. That is, it is not necessarily something that is institutionalized and is done in schools.
} 
This is, however, the significance of education for non-kin and what supports altruism in humans.

\section{Adaptive significance of education}

Compared with learning, the adaptive significance of education is rarely considered. The adaptive significance of learning is evident in the ability to respond to fluctuating environments quickly, which suggests that it has evolved via natural selection. So, what about education? As Caro and Hauser (1992) stated, active teaching is performed "at some cost or at least without obtaining an immediate benefit for itself," which means that education is an altruistic behavior that benefits the pupils at a cost. Thus, the evolution of education can be considered in the context of the evolution of altruistic behavior. The study by Fogarty et al. (2011) is one of the few to analyze the evolution of active teaching using a mathematical model. In their simple genetic model, a single tutor transmits adaptive information to a related pupil at a cost. The model indicated that teaching can evolve when its costs are outweighed by the inclusive fitness benefits that result from the tutor's relatives being more likely to acquire valuable information. It also suggested, however, that there is a narrow range of traits for which teaching would be efficacious because in some conditions, pupils can easily acquire the information on their own by copying others. The assumption here is that valuable information is transmitted from a tutor to a pupil, such as knowledge and skills that benefit the pupil, i.e., a kind of property. Nonetheless, Fogarty et al. (2011) pointed out that there are some differences from other properties: for example, the information taught can be retransmitted to other individuals without being consumed.

How did human altruism evolve initially? The opinions range from the belief that humans are not special compared with other species (e.g., West et al., 2021) to an evolutionary process unique to humans has occurred (e.g., Gintis et al., 2003). For a gene to increase in frequency within a population, the fitness of individuals carrying the gene must be higher, on average, than that of individuals without the gene. If one individual lowers its fitness through altruistic behavior and the fitness of other individuals with the same gene increases as a result, the average fitness of the gene will increase, which will increase its frequency in the population. The Price equation modeled the conditions under which a gene increases its frequency in a population (Price, 1970), and positive assortment is derived from it as a condition under which genes involved in altruistic behavior can increase their frequency (Pepper \& Smuts, 2002). That is, in a population divided into several groups, if the variance within a group is smaller than the variance between groups, genes involved in altruistic behavior will increase in frequency within the population. The inclusive fitness theory of Hamilton (1964a, 1964b) can be derived from the Price equation because kin groups can be regarded as groups with strong positive assortment (Hamilton, 1970). Although some models suggest that altruistic behavior can evolve without such relatedness among individuals, a recent study examining the previous models (Kay et al., 2020) concluded that all models in which altruism can evolve in the absence of relationships "provide 'back- handed' validation that endorses Hamilton's explanation of altruism" (Bourke, 2021). For humans, the first tutors are our parents and other family members, from whom we learn a great deal. As Fogarty et al. (2011) demonstrated, the teaching of kin can be explained by the inclusive fitness theory. However, humans also educate non-kin, and such education is organized on a large scale, especially in modern times.

Traditionally, explanations of the evolution of altruistic behavior in humans can be divided into two main categories: kin selection and reciprocal altruism that explains altruistic behavior among non-kin (Trivers, 1971). However, considering multi-level selection, kinship is only one of the conditions under which positive assortment is guaranteed. If individuals with genes involved in altruistic behavior interact with each other more frequently than the overall frequency of the population, altruism will evolve according to that degree. Moreover, as many kin live in close spatial proximity to each other, spatial proximity promotes positive assortment; however, it is a sufficient condition, not a necessary one. Even if they are not spatially close to each other, when individuals with genes involved in altruistic behavior form a network and interact exclusively with each other, there is room for multi-level selection to occur. For reciprocal altruism to work, the cost of altruism should be compensated for later, directly or indirectly. In other words, if we can eliminate freeriders and interact socially only with those who will be sure to return the favor (individuals who share reciprocal genes, so to speak), reciprocal altruism uses the same model as multi-level selection. Indeed, it has been reported that humans have various cognitive functions that are adapted for positive assortment, such as the detection of cheaters and altruists (e.g., Cosmides \& Tooby, 1992; Oda, Yamagata et al., 2009; Oda, Naganawa et al., 2009; Oda et al., 2021) and memory bias for free-riders (e.g., Oda \& Nakajima, 2010). Although these cognitive functions are thought to be for direct reciprocity between any two persons, the importance of reputation in indirect reciprocity has been noted (e.g., Nowak \& Sigmund, 1998). Such labeling by reputation can also be interpreted to result in reinforcement of positive assortment of the tendency of reciprocity. Moreover, studies of competitive altruism show that prosocial individuals are more likely to be chosen as partners for social interaction and potential spouses (e.g., Hardy \& van Vugt, 2006). Such competitive altruism also can be interpreted as reinforcing the positive assortment of altruists.

Some researchers who advocate multi-level selection argue that culture is an important factor that has strengthened positive assortment because culture functions as a marker distinguishing groups (cultural group selection; e.g., Henrich, 2004). Many cultural elements in humans, especially customs such as dress codes and manners, are transmitted and shared in a group via education. While this transmitted information does not increase the pupils' fitness directly, it serves as a marker and increases group cohesion and differences from other groups. Cultural group selection could compensate for the cost of education.

Thus, reciprocal altruism, which has traditionally been treated separately from kin selection, can also be explained in a unified manner by the concept of positive assortment. However, a genetic basis for reciprocity is not a necessary 
condition for the evolution of reciprocal altruism. Reciprocity can be learned as a pure acquired trait: Even if the genes involved in reciprocity do not increase inclusive fitness, reciprocity will be maintained if there is a later reward for the cost paid. However, free-rider intrusion is always possible when positive assortment is weak. This is also true for teaching knowledge and skills as property. When they are transmitted to others with whom the reciprocal genes are unlikely to be shared at a cost, there must be a return for that cost. In modern society, education is organized and commercialized, and teachers receive monetary compensation for their education. This is not limited to the modern world: In smaller traditional societies, people might have been rewarded (e.g., with food) for providing knowledge (e.g., how to make tools). Reciprocal altruism is possible without positive assortment of genetic traits if mutually beneficial social relationships can be created culturally. One of the proximate factors that brings about reciprocity is norms. Norms of reciprocity can be maintained by cultural transmission. If members of a social network share norms of reciprocity, indirect reciprocity will be maintained regardless of genetic relatedness. Education in humans has been conducted mainly by language, which is a very efficient means of communication that can convey information to many people at once (Dunbar, 1993). The transmission of norms via education would be more effective than transmission via genes. Humans have likely been able to form large societies and build civilizations based on cooperation due to the norms of reciprocity spread through education.

\section{Niche construction by education}

Niche construction is the process whereby organisms modify their own environment (Laland et al., 2016). Reciprocal relationships in a group can be viewed as a kind of social environment for members of the group. Since norms of reciprocity can be spread through cultural transmission, active teaching of the norms could be interpreted as niche construction of a social environment. As mentioned above, education is the act of transmitting concepts such as norms and transforming the behavior of pupils. Even if there is some cost to educating others with whom the reciprocal genes are unlikely to be shared, the benefit is likely worth the cost if it allows tutors to build a niche of reciprocal relationships. Indeed, a theoretical study by Rendell et al. (2011) suggests that the cultural learning that emerges in local niche construction triggers a process with dynamics similar to those of runaway sexual selection, resulting in the selection of costly genetic traits. That is, even if there is a genetic cost to transmitting norms of reciprocity through education, active teaching of the norms can evolve if a niche of reciprocal relationships is constructed as a result. This concept might be similar to the social niche construction proposed by Yamagishi and Hashimoto (2016). The social niche construction model understands culture-specific mental and behavioral characteristics as tools for adaptation to a social environment; simultaneously, the very behaviors adapted by using these tools construct the environment to which one should adapt (social niche). The difference between this and my models is that the social niche construction model assumes that the sociocultural environment is created unconsciously via an interaction with mind tools, while my model assumes that the environment is consciously and actively created through education.

It has been said that humans might have evolved traits that are specialized for teaching because cultural transmission through education is very important for humans (e.g., Ando, 2016; Csibra \& Gergely, 2009). Moreover, it has also been noted that some cognitive traits are adapted to cultural transmission, such as conformity bias (Henrich \& Boyd, 1998). As mentioned above, when teaching kin knowledge as a property, the cost of teaching would be compensated for by increasing the degree of inclusive fitness. This mechanism originally evolved via kin selection (i.e., to increase the fitness of shared genes), but as human societies became larger and more complex, this mechanism might have come to be used to transmit cultural factors, such as norms that are not directly related to genes. As societies grew, the division of labor increased, and skills became more specialized and sophisticated. In this situation, cultural transmission through education of non-kin would become more important, but compensation for the cost of education is still necessary. Education in such a situation would have required not only the provision of knowledge but also the transmission of moral norms, such as reciprocity and loyalty to the in-group. The reciprocal niche constructed would have provided an environment in which altruism based on genes could also be sustained. That is, education and reciprocal altruism could have co-evolved. ${ }^{2}$ This manuscript simply describes an idea, and more detailed examinations using mathematical models or archeological evidence are needed. The transmission of values, morals, beliefs, and habits through massive education is an exclusively human trait. The future development of the evolutionary science of education is expected.

\section{Acknowledgement}

I appreciate the reviewer's helpful comments. This work was supported by JSPS KAKENHI Grant Number $20 \mathrm{H} 01755$.

\section{References}

Ando, J. (2016). Shinka kyoikugaku towa nanika: Kyoiku eno seibutsugakuteki apurochi [Introduction to evolutionary science of education: A biological approach toward education]. Tetsugaku, 136, 195-236. https://koara.lib.keio.ac.jp/xoonips/modules/xoonips/ detail.php?koara_id=AN00150430-00000136-0195

Bourke, A. F. G. (2021). The role and rule of relatedness in altruism. Nature, 590, 392-394. https://doi.

\footnotetext{
${ }^{2}$ Obviously, active teaching in humans has a genetic basis and unique biological characteristics. In addition, time and energy costs of education reduce the degree of biological fitness. However, as with many other human traits, education as an institution could have been established by adding cultural factors on such biological bases. It would be difficult to clarify when education, customary teaching behavior toward non-kin, originated in human evolutionary history. As mentioned in this manuscript, however, such education might have become necessary in a social environment where a society has become more complex to some extent, where the division of labor had advanced and skills have become more specialized, and where reciprocal exchange of knowledge and skills, as well as material goods, had become more important.
} 
org/10.1038/d41586-021-00210-z

Cambridge University Press. (n.d.). Instruction, coaching, and counseling. In Cambridge Dictionary. Retrieved May 20, 2021, from https:/dictionary.cambridge.org/ dictionary/english/

Caro, T. M., \& Hauser, M. D. (1992). Is there teaching in nonhuman animals? Quarterly Journal of Biology, 67(2), 151-174. https://doi.org/10.1086/417553

Cosmides, L., \& Tooby, J. (1992). Cognitive adaptations for social exchange. In J. H. Barkow, L. Cosmides, \& J. Tooby (Eds.), The adapted mind: Evolutionary psychology and the generation of culture (pp. 163228). Oxford University Press.

Csibra, G., \& Gergely, G. (2009). Natural pedagogy. Trends in Cognitive Sciences, 13(4), 148-153. https:// doi.org/10.1016/j.tics.2009.01.005

Dunbar, R. I. M. (1993). Coevolution of neocortical size, group size and language in humans. Behavioral and Brain Sciences, 16(4), 681-694. https://doi.org/10.1017/ S0140525X00032325

Education. (2021, May 20). In Wikipedia. https:// en.wikipedia.org/wiki/Education

Fogarty, L., Strimling, P., \& Laland, K. N. (2011). The evolution of teaching. Evolution, 65(10), 2760-2770. https://doi.org/10.1111/j.1558-5646.2011.01370.x

Franks, N. R., \& Richardson, T. (2006). Teaching in tandem-running ants. Nature, 439, 153. https://doi. org $/ 10.1038 / 439153 a$

Gintis, H., Bowles, S., Boyd, R., \& Fehr, E. (2003). Explaining altruistic behavior in humans. Evolution and Human Behavior, 24(3), 153-172. https://doi. org/10.1016/S1090-5138(02)00157-5

Hamilton, W. D. (1964a). The genetical evolution of social behavior. I. Journal of Theoretical Biology, 7(1), 1-16. https://doi.org/10.1016/0022-5193(64)90038-4

Hamilton, W. D. (1964b). The genetical evolution of social behavior. II. Journal of Theoretical Biology, 7(1), 17-52. https://doi.org/10.1016/0022-5193(64)90039-6

Hamilton, W. D. (1970). Selfish and spiteful behaviour in an evolutionary model. Nature, 228, 1218-1220. https://doi.org/10.1038/2281218a0

Hardy, C. L., \& van Vugt, M. (2006). Nice guys finish first: The competitive altruism hypothesis. Personality and Social Psychology Bulletin, 32(10), 1402-1413. https:// doi.org/10.1177/0146167206291006

Henrich, J. (2004). Cultural group selection, coevolutionary processes and large-scale cooperation. Journal of Economic Behavior \& Organization, 53(1), 3-35. https://doi.org/10.1016/S0167-2681(03)00094-5

Henrich, J. \& Boyd, R. (1998). The evolution of conformist transmission and the emergence of betweengroup differences. Evolution and Human Behavior, 19(4), 215-241. https://doi.org/10.1016/S10905138(98)00018-X

Kay, T., Keller, L., \& Lehman, L. (2020). The evolution of altruism and the serial rediscovery of the role of relatedness. Proceedings of the National Academy of Sciences of the United States of America, 117(46), 28894-28898. https://doi.org/10.1073/pnas.2013596117

Kyōiku kihonhō [Basic Act on Education], Act No. 120 of 2006, translated in (Japanese Law Translation [JLT DS]), http://www.japaneselawtranslation.go.jp/law/ detail/?id $=2442 \& v m=04 \&$ re $=01 \&$ new $=1$

Laland, K., Matthews, B., \& Feldman, M. W. (2016). An introduction to niche construction theory. Evolutionary Ecology, 30, 191-202. https://doi. org/10.1007/s10682-016-9821-z
Liszkowski, U., Carpenter, M., Striano, T., \& Tomasello, M. (2006). 12- and 18-month-olds point to provide information for others. Journal of Cognition and Development, 7(2), 173-187. https://doi.org/10.1207/ s15327647jcd0702_2

Meng, X., \& Hashiya, K. (2014). Pointing behavior in infants reflects the communication partner's attentional and knowledge states: A possible case of spontaneous informing. PLoS ONE, 9(9), e107579. https://doi.org/10.1371/journal.pone.0107579

Nowak, M. A., \& Sigmund, K. (1998). Evolution of indirect reciprocity by image scoring. Nature, 393, 573-577. https://doi.org/10.1038/31225

Oda, R., \& Nakajima, S. (2010). Biased face recognition in the Faith Game. Evolution and Human Behavior, 31(2), 118-122. https://doi.org/10.1016/ j.evolhumbehav.2009.08.005

Oda, R., Naganawa, T., Yamauchi, S., Yamagata, N., \& Matsumoto-Oda, A. (2009). Altruists are trusted based on non-verbal cues. Biology Letters, 5(6), 752754. https://doi.org/10.1098/rsbl.2009.0332

Oda, R., Tainaka, T., Morishima, K., Kanematsu, N., Yamagata-Nakashima, N., \& Hiraishi, K. (2021). How to detect altruists: Experiments using a zeroacquaintance video presentation paradigm. Journal of Nonverbal Behavior, 45(2), 261-279. https://doi. org/10.1007/s10919-020-00352-0

Oda, R., Yamagata, N., Yabiku, Y., \& Matsumoto-Oda, A. (2009). Altruism can be assessed correctly based on impression. Human Nature, 20, 331-341. https://doi. org/10.1007/s12110-009-9070-8

Pepper, J. W., \& Smuts, B. B. (2002). A mechanism for the evolution of altruism among nonkin: Positive assortment through environmental feedback. The American Naturalist, 160(2), 205-213. https://doi. org $/ 10.1086 / 341018$

Price, G. R. (1970). Selection and covariance. Nature, 227 , 520-521. https://doi.org/10.1038/227520a0

Raihani, N. J., \& Ridley, A. R. (2008). Experimental evidence for teaching in wild pied babblers. Animal Behaviour, 75(1), 3-11. https://doi.org/10.1016/ j.anbehav.2007.07.024

Rendell L., Fogarty L., \& Laland K. N. (2011). Runaway cultural niche construction. Philosophical Transactions of the Royal Society B: Biological Sciences, 366(1566), 823-835. https://doi.org/10.1098/ rstb. 2010.0256

Thornton, A., \& McAuliffe, K. (2006). Teaching in wild meerkats. Science, 313(5784), 227-229. https://doi. org/10.1126/science.1128727

Tinbergen, N. (1963). On aims and methods in ethology. Zeitschrift für Tierpsychologie, 20(4), 410-433. https://doi.org/10.1111/j.1439-0310.1963.tb01161.x

Trivers, R. L. (1971). The evolution of reciprocal altruism. The Quarterly Review of Biology, 46(1), 35-55. https:// doi.org/10.1086/406755

West, S. A., Cooper, G. A., Ghoul, M. B., \& Griffin, A. S. (2021). Ten recent insights for our understanding of cooperation. Nature Ecology \& Evolution, 5, 419-430. https://doi.org/10.1038/s41559-020-01384-x

Yamagishi, T., \& Hashimoto, H. (2016). Social niche construction. Current Opinion in Psychology, 8, 119124. https://doi.org/10.1016/j.copsyc.2015.10.003 